\title{
Design of a Gd-DOTA-Phthalocyanine Conjugate Combining MRI Contrast Imaging and Photosensitization Properties as a Potential Molecular Theranostic
}

\author{
Duygu Aydın Tekdaş ${ }^{1}$, Ruslan Garifullin ${ }^{2}$, Berna Şentürk ${ }^{2}$, Yunus Zorlu ${ }^{1}$, Umut Gundogdu ${ }^{3}$, Ergin \\ Atalar $^{3,4}$, Ayse B. Tekinay ${ }^{2}$, Alexander A. Chernonosov ${ }^{5}$, Yusuf Yerli ${ }^{6}$, Fabienne Dumoulin ${ }^{1}$, Mustafa \\ O. Guler ${ }^{2}$, Vefa Ahsen ${ }^{1}$ and Ayşe Gül Gürek*1 \\ ${ }^{1}$ Department of Chemistry, Gebze Institute of Technology, Kocaeli, Turkey \\ ${ }^{2}$ Institute of Materials Science and Nanotechnology, National Nanotechnology Research Center (UNAM), Bilkent University, \\ Ankara, Turkey \\ ${ }^{3}$ National Magnetic Resonance Research Center (UMRAM), Bilkent University, Ankara, Turkey \\ ${ }^{4}$ Department of Electrical and Electronics Engineering, Bilkent University, Ankara, Turkey \\ ${ }^{5}$ Institute of Chemical Biology and Fundamental Medicine, Novosibirsk, Russia \\ ${ }^{6}$ Physics Department, Arts and Science Faculty, Yildiz Technical University, Istanbul, Turkey \\ Received 27 May 2014, accepted 6 August 2014, DOI: 10.1111/php.12332
}

\begin{abstract}
The design and synthesis of a phthalocyanine - Gd-DOTA conjugate is presented to open the way to novel molecular theranostics, combining the properties of MRI contrast imaging with photodynamic therapy. The rational design of the conjugate integrates isomeric purity of the phthalocyanine core substitution, suitable biocompatibility with the use of polyoxo water-solubilizing substituents, and a convergent synthetic strategy ended by the use of click chemistry to graft the Gd-DOTA moiety to the phthalocyanine. Photophysical and photochemical properties, contrast imaging experiments and preliminary in vitro investigations proved that such a combination is relevant and lead to a new type of potential theranostic agent.
\end{abstract}

\section{INTRODUCTION}

Theranostics is one of the promising ways to personalized medicine, more especially against cancer, combining diagnostic and therapeutic effects $(1,2)$. Most of theranostics are nanoobjects as they allow easily combining the different features required (3), when molecular theranostics are rather rare due to the difficulty of combining several properties and effects in a unique chemical derivative. Since the premises of modern photodynamic therapy, the drawbacks of the first-generation of photosensitizers, mainly due to their polymeric poorly characterizable structures have been overcome by the development of second-generation of photosensitizers, consisting mainly of molecular tetrapyrroles of well-defined structures and tailorable properties (4). The third generation of photosensitizers combines imaging agents and photosensitizers to have the patient benefiting from a "see and treat" process (5), and theranostics quickly took place in the photodynamic therapy field. Among the different types of photosensitizers, porphyrins $(6)$ and phthalocyanines $(7,8)$ are particularly

*Corresponding author email: gurek@gyte.edu.tr (Ayşe Gül Gürek)

C 2014 The American Society of Photobiology employed. $\mathrm{Zn}$ (II) phthalocyanines offer the advantage of its nearinfra red absorption, centered at $700 \mathrm{~nm}$ and adjustable by playing on the substitution pattern $(9,10)$. Near-infrared red absorption has the double advantage of a deeper penetration of the light into tissues, and to fit the biological therapeutic window a biological components does not absorb at these wavelengths. Besides, phthalocyanines are extremely stable, compared for example to chlorins absorbing at similar wavelengths but less photostable (11). A wide range of nanoparticles has been reported (12-15), when only a few examples of molecular theranostic for PDT are described $(16,17)$. In most cases, imaging properties are fluorescence-based, phthalocyanines being intrinsically good fluorescent probes (18). Nevertheless, labeling of porphyrins and phthalocyanines by radioelements (19), such as ${ }^{18} \mathrm{~F}$ radiolabeling for PET imaging is reported (20).

Nowadays, computer tomography is the most common imaging technique, PET being the most common for tumors. Contrast magnetic resonance imaging (MRI) is an imaging modality accessible in radiological practice, particularly for the identification and characterization of delicate tissue pathologies, especially solid tumors in cancer, as a non-invasive diagnostic imaging technique utilized within clinical and biomedical examination. The affectability and specificity, and consequently differentiation of MR images, might be further upgraded by the utilization of responsive contrast agents. The majority of MRI contrast agents are paramagnetic complexes made of cyclen-based chelates of lanthanide ions, generally gadolinium $\left(\mathrm{Gd}^{3+}\right)$-based chelates $(21-$ 23). A wide sort of paramagnetic chelates based on Gd(III), have been contrived as $T_{1}$ contrast agents (positive contrast agents) to create a large magnetic moment. Such complexes are known to exhibit nephrotoxic effects (24). This prompts researchers to direct their efforts toward new imaging techniques. These effects are still balanced by their powerful imaging properties. At present, Gd-based contrast agents have been employed in $>40 \%$ of MRI scans, acting an important role in contrast enhanced MRI studies (25-28). Diethylene triamine pentaacetic acid Gd complexes are the most widely used ones, as is the commercially 
available Magnevist ${ }^{\circledR}$, Omniscan ${ }^{\circledR}$ being a bismethylamide substituted diethylene triamine pentaacetic acid Gd complex (29). The efficacy of these contrast agents depends on the interchanging of water between the bulk solvent and the coordination sphere. The swapping scale of bound water relies upon nature of the ligand and the metal ion. Complexes made with the chelator DOTA (1,4,7,10-tetraazacyclododecane-1,4,7,10-tetraacetic acid) exhibit the fastest rate of bound water.

For the last several years, our laboratory has focused its research on developing NIR absorbing photosensitizers with a phthalocyanine core (30-34), with enhanced efficacy thanks to various strategies: targeting (35), dual antivascular action $(36,37)$, nanoparticles functionalization $(38,39)$. We then wished to explore the possibility to produce PDT sensitizers having MRI contrast imaging properties, to enlarge the range of available techniques for dual imaging and photosensitization, and obtain a novel type of theranostic agent. We selected a DOTA unit complexing a gadolinium atom as the MRI contrast agent, coupled to a $\mathrm{Zn}$ phthalocyanine core with known photosensitizing properties. To our knowledge, such strategy has not been developed yet: the only DOTA-phthalocyanine conjugate reported so far includes ${ }^{68} \mathrm{Ga}$ to be used as PET/fluorescent dual imaging probe (40).

In this paper, we report the design and the synthesis as well as the theranostic dual photodynamic and imaging potential of the phthalocyanine-GdDOTA conjugate $\mathbf{8}$.

\section{MATERIALS AND METHODS}

General methods. ${ }^{1} \mathrm{H}$ and ${ }^{13} \mathrm{C}$ nuclear magnetic resonance (NMR) spectra were recorded by Varian $500 \mathrm{MHz}$ spectrometer at 500 and $125 \mathrm{MHz}$, respectively. Unless otherwise stated, chemical shifts are reported in ppm and referenced to residual solvent resonance peaks $\left(\mathrm{CDCl}_{3}: 7.26 \mathrm{ppm}\right.$ for ${ }^{1} \mathrm{H}$ and $77.2 \mathrm{ppm}$ for ${ }^{13} \mathrm{C}, \mathrm{DMF}_{-} \mathrm{d}_{7}: 8.03,2.92,2.75 \mathrm{ppm}$ for ${ }^{1} \mathrm{H}$ and 163.15, 34.89, $29.76 \mathrm{ppm}$ for ${ }^{13} \mathrm{C}$, DMSO-d $\mathrm{d}_{6}$ : $2.50 \mathrm{ppm}$ for ${ }^{1} \mathrm{H}$ and $39.51 \mathrm{ppm}$ for ${ }^{13} \mathrm{C}$ ). Normal resolution mass spectra were recorded on a LCQ-ion trap (Thermo Finnigan, San Jose, CA), equipped with an ES (Electrospray) ionization source. High-resolution MALDI spectra for $\mathbf{6}$ and $\mathbf{8}$ were obtained as follows: the matrix solution was $20 \mathrm{mg} \mathrm{mL}^{-1}$ 2,5-dihydroxy benzoic acid (DHB) in 30\% acetonitrile/70\% aqueous $0.1 \%$ trifluoroacetic acid (v/v) for measuring conjugate 8. Sample was dissolved in Milli-Q water and one $\mu \mathrm{L}$ was mixed with $1 \mu \mathrm{L}$ of matrix. One $\mu \mathrm{L}$ of the resulting mixture was spotted on the MTP 384 polished steel plate. Sample was allowed to air dry and crystallizes before the target was loaded into the mass spectrometer. Mass spectra were obtained in positive reflectron ion mode using Autoflex Speed MALDI-TOF mass spectrometer (Bruker Daltonics, Bremen, Germany) with an acceleration voltage of $19 \mathrm{kV}$ and laser frequency of $1 \mathrm{~Hz}$. The laser power was set at $40 \%$ to $100 \%$ of the maximum. Signals from 500 shots were accumulated for each spectrum. For external calibration the standard peptide mixture "Peptide Mix II" (Bruker Daltonics) was used. ICP-MS was performed on Thermo $\mathrm{X}$ series II. Each sample was acquired using 1 survey run (10 sweeps) and 3 main (peak jumping) runs (100 sweeps). The isotopes selected were ${ }^{156,157} \mathrm{Gd}$ for acquisition, with ${ }^{115} \mathrm{In},{ }^{165} \mathrm{Ho}$ and ${ }^{209} \mathrm{Bi}$ as internal standards for data interpolation and machine stability. Conjugate $8(1 \mathrm{mg})$ was dissolved in concentrated nitric acid $(1 \mathrm{~mL})$ and sonicated for $15 \mathrm{~min}$. After appropriate dilution in $5 \%$ aq. $\mathrm{HNO}_{3}$ solution (v/ $\mathrm{v} \%$ ) samples were fed to ICP-mass spectrometer. Ratio of $\mathrm{Zn}$ to $\mathrm{Gd}$ metal ions was calculated based on obtained concentration values. IR spectra were recorded on a Perkin Elmer 100 FTIR spectrometer. All solvents and chemicals were of reagent-grade quality, purchased from Sigma-Aldrich Chemical Co. and Merck, and used as received. 1,3-diphenylisobenzofuran (DPBF) was purchased from Fluka. Unless otherwise indicated, organic extracts were dried over anhydrous sodium sulfate and concentrated under reduced pressure using a rotary evaporator. Purification by column chromatography was performed using Merck Kieselgel 60 silica gel as the stationary phase. Ultra-pure water was obtained from a Milli-Q Water System (Sartorius arium 611 UV). 4,5-bis(4,7, 10-trioxaundecane1-sulfonyl)phthalonitrile (41), 4-(carboxyethylsulphanyl) phthalonitrile 2 (42), 3-azido-aminopropylamine (43) and $\mathrm{Gd}(\mathrm{III})$ derivatives (Gd-595 MW $595 \mathrm{~g} \mathrm{~mol}^{-1}$ ) $(44,45)$ were synthesized according to previously described procedures.

Syntheses. Synthesis ofN-(3-azidopropyl)-3-((3,4-dicyanophenyl)thio) propanamide (4). 4-Carboxyethylsulfanyl phthalonitrile 2 (300 mg, $1.3 \mathrm{mmol})$ was dissolved in anhydrous THF $(5 \mathrm{~mL})$ under argon atmosphere, then thionyl chloride $(1.6 \mathrm{~g}, 13.3 \mathrm{mmol})$ in anhydrous toluene $(5 \mathrm{~mL})$ was added and the solution was refluxed for $3 \mathrm{~h}$. Thereafter, solvents and excess of thionyl chloride were evaporated under reduce pressure. Brown oil was dissolved in anhydrous THF $(5 \mathrm{~mL})$ and 1azido-3-aminopropane 3 (390 $\mathrm{mg}, 3.9 \mathrm{mmol}$ ) (as a free base) in anhydrous THF $(5 \mathrm{~mL})$ was added slowly drop by drop, then the mixture was refluxed for $3 \mathrm{~h}$. The crude product was concentrated under reduce pressure, suspended in water and extracted three times with ethyl acetate. Organic layer was then extracted with brine, dried over anhydrous $\mathrm{Na}_{2} \mathrm{SO}_{4}$ and purified by column chromatography on silica with dichloromethane/ethyl acetate 100:1 as eluent followed by recrystallization from ethanol yielding yellowish solid $(280 \mathrm{mg}, 68 \%)$. FT-IR $\left(\mathrm{cm}^{-1}\right)$ 3229 (NH), 3093 (ArH), 2929-2850 ( $\left.\mathrm{CH}_{2}\right), 2230(\mathrm{CN}), 2083\left(\mathrm{~N}_{3}\right)$ 1631 (CO), 1583 (NH-CO), 1477 (NH-CO). ${ }^{1} \mathrm{H}$ NMR (500 MHz, $\left.\mathrm{CDCl}_{3}, \delta \mathrm{ppm}\right): 1.75\left(\mathrm{p}, 2 \mathrm{H}, \mathrm{CH}_{2}\right), 2.02\left(\mathrm{t}, 2 \mathrm{H}, \mathrm{N}_{3}-\mathrm{CH}_{2}\right), 3.30(\mathrm{~m}, 6 \mathrm{H}$, $\left.\mathrm{SCH}_{2}, \mathrm{CH}_{2}, \mathrm{NHCH}_{2}\right), 5.9(\mathrm{~s}, \mathrm{NH}), 7.51(\mathrm{~d}, \mathrm{~d}, 1 \mathrm{H}, \mathrm{ArCH}), 7.55$ (s, d, $1 \mathrm{H}, \operatorname{ArH}), 7.60$ (d, $1 \mathrm{H}, \mathrm{ArH}) .{ }^{13} \mathrm{C} \mathrm{NMR}\left(125 \mathrm{MHz}, \mathrm{CDCl}_{3}, \delta \mathrm{ppm}\right)$ : $27.38 \quad\left(\mathrm{NH}_{2} \mathrm{CH}_{2} \mathrm{CH}_{2} \mathrm{~N}_{3}\right), \quad 28.64 \quad\left(\mathrm{NHCH}_{2}\right), \quad 34.97 \quad\left(\mathrm{SCH}_{2}\right), \quad 37.45$ $\left(\mathrm{SCH}_{2} \mathrm{CH}_{2}\right), 49.38\left(\mathrm{CH}_{2} \mathrm{~N}_{3}\right), 111.07(\mathrm{CN}), 115.10(\mathrm{Ar}), 115.53(\mathrm{CN})$, $116.24(\mathrm{CN}), 130.20$ (Ar), 133.57 (Ar), 146.41 (Ar-S), 169.79 (CO). MS (ESI) $\mathrm{m} / \mathrm{z}[\mathrm{M}+\mathrm{Na}]^{+} 337.09 . \mathrm{m} / \mathrm{z}$ calculated for $\mathrm{C}_{14} \mathrm{H}_{14} \mathrm{~N}_{6} \mathrm{OS}[\mathrm{M}]^{+}$ 314.37.

Synthesis of 2-(N-(3-azidopropyl)-(3-thiopropane)amide) 9,10,16,17, 23,24-(1-mercapto-4,7,10-trioxaundecane) Zn(II) phthalocyanine (6) . N(3-azidopropyl)-3-((3,4-dicyanophenyl)thio)propanamide $4 \quad$ (50 $\mathrm{mg}$, $0.16 \mathrm{mmol})$ and 4,5-bis(4,7,10-trioxaundecane-1-sulfonyl) phthalonitrile 1 (670 mg, $1.44 \mathrm{mmol}$ ) were dissolved in anhydrous dimethylaminoethanol $(2 \mathrm{~mL})$ under argon atmosphere and stirred for $20 \mathrm{~min}$. Then $\mathrm{Zn}(\mathrm{OAc})_{2}$ (150 mg, $0.80 \mathrm{mmol}$ ) was added and solution was refluxed for further $1 \mathrm{~h}$ at $120^{\circ} \mathrm{C}$, then the reaction was cooled down. The reaction mixture was evaporated under reduce pressure. A crude green mixture of symmetric derivative $\mathbf{5}$ and desired asymmetric derivative $\mathbf{6}$ was purified by column chromatography over bio-beads using $\mathrm{CH}_{2} \mathrm{Cl}_{2}$ as eluent, then the two derivatives were separated on preparative silica gel TLC using $\mathrm{CH}_{2} \mathrm{Cl}_{2}: \mathrm{CH}_{3} \mathrm{CH}_{2} \mathrm{OH}(13: 1)$ as the eluent. Yield: $28 \%(68 \mathrm{mg})$. (FT-IR $\left(\mathrm{cm}^{-1}\right) 3308(\mathrm{NH}), 2922,2857\left(\mathrm{CH}_{2}\right), 2093\left(\mathrm{~N}_{3}\right), 1641$ (amide $\left.\mathrm{CO}\right) .{ }^{1} \mathrm{H}$ NMR $\left(500 \mathrm{MHz}, \mathrm{DMF}_{7}, \delta \mathrm{ppm}\right): 1.28(\mathrm{~s}, \mathrm{H}, \mathrm{NH}), 1.87(\mathrm{t}, 2 \mathrm{H}$, $\left.\mathrm{CH}_{2} \mathrm{~N}_{3}\right), 3.25-3.29\left(\mathrm{~m}, 18 \mathrm{H}, \mathrm{OCH}_{3}\right), 3.34-3.41\left(\mathrm{~m}, 2 \mathrm{H}, \mathrm{CH}_{2} \mathrm{CH}_{2} \mathrm{~N}_{3}\right)$, $3.48-3.53\left(\mathrm{~m}, 6 \mathrm{H}, \mathrm{COCH}_{2}, \mathrm{SCH}_{2}, \mathrm{NHCH}_{2}\right), 3.58-3.67\left(\mathrm{~m}, 12 \mathrm{H}, \mathrm{SCH}_{2}\right)$, 3.72-3.90 (m, 48H, $\left.\mathrm{OCH}_{2}\right), 4.16-4.19\left(\mathrm{~m}, 12 \mathrm{H}, \mathrm{SCH}_{2} \mathrm{CH}_{2} \mathrm{O}\right), 8.22(\mathrm{br}, s$, $2 \mathrm{H}, \mathrm{ArH}), 8.84-9.26(\mathrm{~m}, 7 \mathrm{H}, \mathrm{ArH}) .{ }^{13} \mathrm{C} \mathrm{NMR}\left(125 \mathrm{MHz}, \mathrm{DMF}-\mathrm{d}_{7}, \delta\right.$ ppm): $28.94\left(\mathrm{CH}_{2}\right), 33.23\left(\mathrm{CH}_{2}\right), 33.59\left(\mathrm{CH}_{2}\right), 33.59\left(\mathrm{CH}_{2}\right), 33.75\left(\mathrm{CH}_{2}\right)$, $35.11\left(\mathrm{CH}_{2}\right), \quad 35.45\left(\mathrm{CH}_{2}\right), \quad 36.45\left(\mathrm{CH}_{2}\right), \quad 48.98\left(\mathrm{CH}_{2} \mathrm{~N}_{3}\right), \quad 58.04\left(\mathrm{OCH}_{3}\right)$, 69.50 $\left(\mathrm{CH}_{2}\right), \quad 69.69\left(\mathrm{CH}_{2}\right), \quad 70.25\left(\mathrm{CH}_{2}\right), \quad 70.43\left(\mathrm{CH}_{2}\right), \quad 70.51\left(\mathrm{CH}_{2}\right), \quad 71.79$ $\left(\mathrm{SCH}_{2}\right), 121.41(\mathrm{Ar}) 135.47(\mathrm{Ar}), 135.66(\mathrm{Ar}), 136.17(\mathrm{Ar}), 137.76(\mathrm{Ar})$, 138.45(Ar), 139.17(Ar), 152.90 (Ar-S), 170.06 (CO). HRMS (MALDITOF) $\mathrm{m} / \mathrm{z}[\mathrm{M}+\mathrm{H}]+$ calculated for $\mathrm{C}_{80} \mathrm{H}_{110} \mathrm{~N}_{12} \mathrm{O}_{19} \mathrm{~S}_{7} \mathrm{Zn} 1833.6252$; found 1833.6336 (mass accuracy $4.58 \mathrm{ppm}$ ). UV-Vis (DMSO) $\lambda \max \mathrm{nm}(\log \varepsilon)$ 371.5 (4.86) and 705.5 (4.93).

Synthesis of 2-(N-(3-Gd595-propyl)-(3-thiopropylamide)-9,10,16,17, 23,24-(1-mercapto-4,7,10-trioxaundecane) Zn(II) phthalocyanine (8). 2( $N$-(3-azidopropyl)-(3-thiopropyl)amide)-9,10,16,17,23,24-(1-mercapto4,7,10 trioxaundecane) $\mathrm{Zn}(\mathrm{II})$ phthalocyanine 6 (40 mg, $0.022 \mathrm{mmol}$ ), Gd-595 (7) (45 mg, $0.077 \mathrm{mmol})$, sodium ascorbate (29 $\mathrm{mg}, 0.15 \mathrm{mmol}$ ) and copper sulfate were dissolved in a water/DMF (1:1) mixture $(1 \mathrm{~mL})$. The mixture was heated at $60^{\circ} \mathrm{C}$ for $48 \mathrm{~h}$, then cooled down and loaded into a dialysis bag with MWCO 2000, and dialyzed for $48 \mathrm{~h}$ against Millipore water. The absence of residual free $\mathrm{Gd}^{3+}$ ion was confirmed with the xylenol orange indicator test in an aqueous solution of the complex 8. The final reaction mixture was lyophilized and run through a BioBeads(C) (BioRad SX2) column using DCM as the eluent. Purification by column chromatography on cellulose with $\mathrm{CH}_{2} \mathrm{Cl}_{2}$ and then DCM/EtOH $(10: 1)$ as solvent gave the desired product. Yield: $45 \%(24 \mathrm{mg})$. FT-IR $\left(\mathrm{cm}^{-1}\right) 3268(\mathrm{NH}), 2870\left(\mathrm{CH}_{2}\right), 1594$ (Gd-595-CO), 1371 (triazole ring). HRMS (MALDI-TOF) $\mathrm{m} / \mathrm{z}[\mathrm{M}+\mathrm{H}]+$ calculated for $\mathrm{C}_{80} \mathrm{H}_{110} \mathrm{~N}_{12} \mathrm{O}_{19} \mathrm{~S}_{7} \mathrm{Zn}$ 2430.7789; found 2430.7882 (mass accuracy $3.82 \mathrm{ppm}$ ). UV-Vis (DMSO) $\lambda \max \mathrm{nm}(\log \varepsilon) 390$ (4.60), 705 (5.01). 
$X$-ray data collection and structure refinement. Unit cell measurements and intensity data collection were performed on an Bruker APEX II QUAZAR three-circle diffractometer using monochromatized Mo K $\alpha$ $\mathrm{X}$-radiation $(\lambda=0.71073 \AA)$ using $\phi$ and $\omega$ technique. Indexing was performed using APEX2 (46). Data integration and reduction were carried out with SAINT V8.27B (47). Absorption correction was performed by multiscan method implemented in SADABS V2012/1 (48). The structure was solved using the direct methods procedure in SHELXS-97 (49) and then refined by full-matrix least-squares refinements on F2 using the SHELXL-97. All non-hydrogen atoms were refined anisotropically using all reflections with $\mathrm{I}>2 \sigma(\mathrm{I})$. C-bound $\mathrm{H}$-atoms were positioned geometrically and refined using a riding mode. The N-bound $\mathrm{H}$ atom was located from the difference Fourier map and restrained to be $0.89 \AA$ from $\mathrm{N}$ atom using DFIX and its position was constrained to refine on its parent $\mathrm{N}$ atom with $\operatorname{Uiso}(\mathrm{H})=1.2 \mathrm{Ueq}(\mathrm{N})$. Crystallographic data and refinement details of the data collection for $\mathbf{4}$ are given in Table S1. The final geometrical calculations and the molecular drawings were carried out with Platon v1.16 (50) and Mercury CSD 3.1 program (51).

EPR measurements. The solution EPR spectrum was recorded in solution (chloroform) with a Jeol JES FA 300 X-bandspectrometer $(8.96 \mathrm{GHz})$ with about $1 \mathrm{~mW}$ microwave power and $100 \mathrm{kHz}$ magnetic field modulation, at room temperature.

Photophysics and photochemistry. Instrumentation. Absorption spectra in the UV-Visible region were recorded with a Shimadzu 2001 UV spectrophotometer. Fluorescence excitation and emission spectra were recorded on a Varian Eclipse spectrofluorometer using $1 \mathrm{~cm}$ pathlength cuvettes at room temperature. Photo-irradiations were done using a General Electric quartz line lamp (300W). A $600 \mathrm{~nm}$ glass cut off filter (Schott) and a water filter were used to filter off ultraviolet and infrared radiations respectively. An interference filter (Intor, $700 \mathrm{~nm}$ with a band width of $40 \mathrm{~nm}$ ) was additionally placed in the light path before the sample. Light intensities were measured with a POWER MAX5100 (Molelectron detector incorporated) power meter.

Fluorescence quantum yield determination. Fluorescence quantum yield $\left(\Phi_{\mathrm{F}}\right)$ was estimated by the comparative method (Eq. 1) $(52,53)$ using unsubstituted $\mathrm{Zn}(\mathrm{II})$ phthalocyanine $(\mathrm{ZnPc})$ as the reference. Reference value of $\Phi_{\mathrm{F}}$ is 0.18 in DMSO for $\mathrm{ZnPc}$ (54)

$$
\Phi_{\mathrm{F}}=\Phi_{\mathrm{F}}(\mathrm{Std}) \frac{\mathrm{F} \cdot \mathrm{A}_{\mathrm{Std}} \cdot \mathrm{n}^{2}}{\mathrm{~F}_{\mathrm{Std}} \cdot \mathrm{A} \cdot \mathrm{n}_{\mathrm{Std}}^{2}}
$$

where $\mathrm{F}$ and $\mathrm{F}_{\mathrm{Std}}$ are the areas under the fluorescence emission curves of the sample and the standard, respectively. A and $A_{S t d}$ are the respective absorbances of the sample and standard at the excitation wavelengths. $\mathrm{n}^{2}$ and $\mathrm{n}_{\text {Std }}^{2}$ are the refractive indices of solvents used for the sample and standard, respectively. The absorbance of the solutions at the excitation wavelength ranged between 0.1 and 0.02 .

Singlet oxygen quantum yield determination. Singlet oxygen quantum yield $\left(\Phi_{\Delta}\right)$ was determined in air using the relative method (55) with $\mathrm{ZnPc}$ (in DMSO) or $\mathrm{ZnPcSmix}$ (in aqueous media) as the reference. DPBF (1,3-diphenylisobenzofuran) and ADMA (anthracene-9,10-bismethylmalonate) were used as chemical quencher for singlet oxygen, respectively in DMSO and aqueous media, using Eq. (2):

$$
\Phi \Delta=\Phi_{\Delta}^{\mathrm{Std}} \frac{\mathrm{R} \cdot \mathrm{I}_{\mathrm{abs}}^{\mathrm{Std}}}{\mathrm{R}^{\mathrm{Std}} \cdot \mathrm{I}_{\mathrm{abs}}}
$$

where $\Phi_{\Delta}^{\text {Std }}$ is the singlet oxygen quantum yield for the standard $\mathrm{ZnPc}$ $\left(\Phi_{\Delta}^{\text {Std }}=0.67\right.$ in DMSO) $(54)$ and $\mathrm{ZnPcSmix}\left(\Phi_{\Delta}^{\text {Std }}=0.45\right.$ in aqueous media) (56) and $\mathrm{R}$ and $\mathrm{R}_{\mathrm{Std}}$ are the DPBF photobleaching rates in the presence of the respective sample and standards, respectively. $I_{a b s} \Phi_{a b s}^{\text {Std }}$ and are the rates of light absorption by the sample and standards, respectively. To avoid chain reactions induced by the initial photo-oxidative product of the reaction between DPBF (or ADMA) and singlet oxygen (56), the concentration of quenchers (DPBF or ADMA) was lowered to $\sim 3 \times 10^{-5} \mathrm{M}$. Solutions of the photosensitizer containing DPBF (or ADMA) were prepared in the dark and irradiated in the Q-band region using the setup described in equipment part. DPBF degradation at $417 \mathrm{~nm}$ and ADMA degradation at $380 \mathrm{~nm}$ (in water) were monitored. The light intensity of $7.05 \times 10^{15}$ photons s $\mathrm{s}^{-1} \mathrm{~cm}^{-2}$ was used for $\Phi_{\Delta}$ determinations.
Photodegradation quantum yield determination. Photodegradation quantum yield $\left(\Phi_{\mathrm{d}}\right)$ determination was carried out using the experimental setup described in literature $(57,58) . \Phi_{\mathrm{d}}$ value was determined using Eq. (3),

$$
\Phi_{\mathrm{d}}=\frac{\left(\mathrm{C}_{0}-\mathrm{C}_{\mathrm{t}}\right) \cdot \mathrm{V} \cdot \mathrm{N}_{\mathrm{A}}}{\mathrm{I}_{\mathrm{abs}} \cdot \mathrm{S} \cdot \mathrm{t}}
$$

where $C_{0}$ and $C_{t}$ are respectively the sample concentrations before and after irradiation, $\mathrm{V}$ is the reaction volume, $\mathrm{N}_{\mathrm{A}}$ the Avogadro's constant, $S$ the irradiated cell area and the irradiation time, $I_{a b s}$ is the overlap integral of the radiation source light intensity and the absorption of the sample. A light intensity of $2.20 \times 10^{16}$ photons $\mathrm{s}^{-1} \mathrm{~cm}^{-2}$ was employed for $\Phi_{\mathrm{d}}$ determinations.

Relaxivity $\left(r_{1}\right)$ measurements. MRI relaxivity measurements were performed on a Siemens 3T TIMTrio Scanner (Siemens Medical Solutions, Erlangen, Germany) at $37^{\circ} \mathrm{C}$. The presence of paramagnetic $\mathrm{Gd}(\mathrm{III})$ in the complexes resulted in an enhancement of the longitudinal relaxation rate of water protons (1/T1). Aqueous solutions of $\mathrm{Gd}(\mathrm{III})$ complexes were prepared at various concentrations $(0.05,0.10,0.20,0.40,0.80$ and $1.60 \mathrm{mM})$. A $3 \mathrm{~mL}$ glass sample holder $(\mathrm{d}=10 \mathrm{~mm})$ was placed in the isocenter of the magnet. Spin-echo pulse sequences with multiple spin echoes of various repetition times were utilized to obtain pixel-by-pixel T1 maps of each sample. T1 relaxation times were measured from large regions of interest and results were inverted to obtain the $R_{1}\left(1 / T_{1}\right)$ relaxation rate in $\mathrm{s}^{-1}$. MR imaging capabilities of the Gd(III) complex was examined at $3 \mathrm{~T}$ with the following parameters; point resolution: $1 \mathrm{~mm}$, number of slices: 3, slice thickness: $2.3 \mathrm{~mm}$, echo time (TE): $7.8 \mathrm{~ms}$, repetition time (TR): 50, 100, 200, 500, 750, 1000, 2000, $7000 \mathrm{~ms} . T_{1}$ values were calculated by fitting recovery times to the following Eq. (4) in Matlab;

$$
f(t)=a\left(1-e^{-t / T 1}\right)+c
$$

The inverse of the longitudinal relaxation time $\left(R_{1}, \mathrm{~s}^{-1}\right)$ was plotted against Gd(III) complex concentration $(\mathrm{mM})$ and fitted to a straight line with $R^{2}>0.99$. The slope of the fitted line was taken as the relaxivity $\left(r_{1}, \mathrm{mM}^{-1} \mathrm{~s}^{-1}\right)$.

Cell viability. Human breast adenocarcinoma cells (MCF-7) were grown to confluence at $37^{\circ} \mathrm{C}$ under $5 \% \mathrm{CO}_{2}$ in Dulbecco's Modified Eagle Serum (DMEM) containing $1 \%$ penicillin/streptomycin, $10 \%$ fetal bovine serum (FBS) and $2 \mathrm{mM}$ L-glutamine. The cells were seeded in 96-well plates at an initial density of $1 \times 10^{4}$ cells/well. $24 \mathrm{~h}$ after cell seeding, phthalocyanine complex was added to final concentrations of $1,5,10,20$ and $50 \mu \mathrm{M}$, respectively $(n=4)$. After $24 \mathrm{~h}, 48 \mathrm{~h}$ and $72 \mathrm{~h}$ incubation, viability of cells was evaluated by using Alamar blue assay according to manufacturer's instructions. SpectraMax M5 microplate reader (Molecular Devices) was used for analysis.

Confocal microscopy. MCF-7 cells were seeded in 24-well plates at an initial cell density of $5 \times 103$ cells/well. After $24 \mathrm{~h}$ incubation period the cells were treated with $10 \mu \mathrm{M}$ conjugate 8 at $37^{\circ} \mathrm{C}$ for $24 \mathrm{~h}$ in a humidified chamber with $5 \% \mathrm{CO}_{2}$. After $24 \mathrm{~h}$, cells were washed three times with phosphate-buffered saline (PBS), fixed with $4 \%$ paraformaldehyde in PBS, covered with mounting medium and coverslip and stored at $-20^{\circ} \mathrm{C}$. The samples were imaged with Zeiss LSM-510 confocal microscope with an oil-immersion $63 \times$ objective lens. An argon laser of $488 \mathrm{~nm}$ wavelength was used.

\section{RESULTS AND DISCUSSION}

\section{Synthesis and characterizations}

On a molecular design point of view, A3B substitution pattern of the phthalocyanine appeared to be the best, one isoindole subunit bearing the DOTA unit and the three other isoindole subunits bearing biocompatible water-solubilizing moieties. The design of such a conjugate and this choice of the A3B substitution pattern, in which one phthalocyanine core is coupled to one Gd-DOTA unit, takes into account the working concentrations in both thera- 
peutic methods, which are both compatible in the micromolecular range (59).

Common drawbacks of phthalocyanines are the regioisomeric mixtures and their important aggregation tendency due to pistacking opportunity between two macrocycles, often enhanced in water. Polyethylene glycol substitution was proved to be a good substitution pattern for photosensitizing phthalocyanines $(30,31)$. To avoid regioisomeric mixtures detrimental to further clinical tests, peripheral disubstitution pattern was selected, using thiol functionalized polyethylene glycol chains (30). If free-base phthalocyanines exhibit good fluorescence, better singlet oxygen generation is observed when the phthalocyanine is coordinated to a metal or a pseudo-metal such as $\mathrm{Zn}$ (II), $\mathrm{Al}(\mathrm{III})$, $\mathrm{Ga}(\mathrm{III}), \mathrm{Si}(\mathrm{IV})$. $\mathrm{Zn}$ metalation is the most common and was selected for these works. The resulting complex designed here is a bimetallic molecule, the Gd-DOTA for the MRI effect and the $\mathrm{Zn}$ metalation of the phthalocyanine for the photodynamic activity.

The choice of the Gd-DOTA unit coupled to a phthalocyanine was likely to satisfy all our requirements for good imaging results: fast water exchange, tenable rotational dynamics and limited internal motion. The efficiency of a contrast agent is expressed by their relaxivity $r_{1}$ and a much higher effectiveness, achievable by tuning its physico-chemical characteristics: the residence time of the water molecule(s) coordinated to the central GdIII ion $(\tau \mathrm{M})$ and the rotational correlation time of the whole molecule $(\tau \mathrm{R})$. In general, the clinically used contrast agents have too slow water exchange rate (long $\tau \mathrm{M}$ ) and too fast molecular tumbling (short $\tau \mathrm{R}$ ) due to their low-molecular-weight nature. As it is known that increasing the molecular size of MRI imaging agent enhances its overall molecular relaxivity, the conjugation to phthalocyanine, which is a molecule of elevated molecular weight, is expected to have a beneficial effect on the imaging properties.

On a synthetic strategy aspect, the Huisgen dipolar addition of click chemistry is a powerful synthetic tool successfully used in tetrapyrrolic functionalization (60) and was selected for the coupling of the DOTA moiety onto the phthalocyanine. To click the known alkynyl DOTA 7 (known as Gd-595) (59), the azidofunctionalized phthalocyanine $\mathbf{6}$ was designed.

A3B phthalocyanines are easily obtained by cyclotetramerization reactions applied to a statistical mixture of two phthalonitriles. The first synthetic strategy envisaged was the preparation of a monocarboxylated phthalocyanine on which introduce the azido function (Scheme 1), but the purification and separation of the desired A3B from the concomitantly formed symmetric derivative proved to be tedious. The alternative synthetic strategy adopted was the preparation of an azidophthalonitrile, used to obtain an A3B azidophthalocyanine, a suitable building block for click chemistry with any molecule bearing a terminal alkyne, and clicked hereafter onto alkynyl DOTA 7.

Azidophthalonitrile $\mathbf{4}$ is a key intermediate, prepared from phthalonitrile 2, amidified with 3-azidopropylamine (43) using $\mathrm{SOCl}_{2}$ in a reasonable $68 \%$ yield, and that could be crystallized from ethanol at room temperature via slow evaporation. ORTEP representation with atomic numbering scheme is shown in Fig. S5. Compound $\mathbf{4}$ crystallizes in a triclinic space group $(P-1)$. The $\mathrm{N}-\mathrm{H}$ and $\mathrm{C}=\mathrm{O}$ bonds in the amide functional group are anti to each other. The amido -NHCO-plane is nearly orthogonal to the phthalonitrile aromatic ring $(\mathrm{C} 3-\mathrm{C} 8)$ with the value of dihedral angle of $76.74^{\circ}$. The $\mathrm{C} \equiv \mathrm{N}$ bond distances of $1.142(3) \AA$ and
1.143(3) $\AA$ are similar to values reported in the literature $(61,62)$. The azido group is not linear with the value of N6-N5-N4 angle of $171.7(2)^{\mathrm{o}}$.

A 9:1 ratio of starting materials has been calculated to lead to the formation of a mixture of only two derivatives: the symmetric A4 and the desired A3B phthalocyanine. This 9:1 ratio was applied to a mixture of starting materials (phthalonitriles $\mathbf{1}$ and 4) which underwent mixed cyclotetramerization in the presence of zinc acetate in dimethylaminoethanol, and led to the symmetric phthalocyanine 5 (identified accordingly to our previous reports (30) and the desired $\mathrm{AAAB}$ phthalocyanine 6, separated by preparative thin layer chromatography. The absence of other derivatives (except traces of $\mathrm{A} 2 \mathrm{~B} 2$ isomers), together with the yield of $28 \%$ for the desired A3B phthalocyanine $\mathbf{6}$, is attributable to the excess of phthalonitrile $\mathbf{1}$ and is excellent for this kind of reaction $(63,64)$. This key synthetic intermediate was characterized by ${ }^{1} \mathrm{H}$ and ${ }^{13} \mathrm{C}$ NMR as well as by MALDI-TOF at high resolution and IR spectroscopy. An intense peak at $2093 \mathrm{~cm}^{-1}$ evidences the presence of the azide function (Fig. S6).

The phthalocyanine-DOTA conjugate $\mathbf{8}$ was obtained by click chemistry. Various conditions were tested for the click reaction. Heating azidophthalocyanine $\mathbf{5}$ in DMF with alkynyl GdDOTA, copper sulfate and sodium ascorbate appeared to be the most suitable conditions, leading to the desired conjugate $\mathbf{8}$ in rather high yield $(45 \%)$. Purification was nevertheless laborious, due to the polarity of the conjugate inducing its sticking to silica gel during chromatographic purifications. NMR spectroscopy is not suitable for paramagnetic compounds, which is the case of conjugate 8. Its structure was ascertained by FT-IR (Fig. S9) and MALDI spectroscopy at high resolution (Fig. 1). The experimental and theoretical isotopic patterns obtained for $\mathbf{8}$ in high-resolution conditions are fitting each other, confirming the structure of desired compound 8 (Fig. 1). The EPR spectrum of conjugate $\mathbf{8}$ in chloroform was recorded in the $0-8000 \mathrm{G}$ range at room temperature (Fig. S11). The broad peak at about $\mathrm{g} \approx 1.997$ in the spectrum belongs to $\mathrm{Gd}^{3+}(\mathrm{S}=7 / 2)$ ions, with a peak-to-peak linewidth, $\Delta H_{\mathrm{pp}} \cong 560 \mathrm{G}$. Since $\mathrm{Gd}^{3+}$ ion is S-state paramagnetic ion, the orbital contribution becomes quenched, resulting in a long relaxation time. The other peaks are background signals from sample tube and cavity. $\mathrm{Gd}^{3+}$ ion has a $4 \mathrm{f}^{7}$ electronic configuration and ${ }^{8} \mathrm{~S}_{7 / 2}$ ground state. Due to zero orbital angular momentum, it is only the trivalent lanthanide whose EPR can be observed at room temperature. The relaxation mechanism of $\mathrm{Gd}^{3+}$ complexes in solution is determined by zero field splitting (ZFS) which is caused by the exchange interactions between unpaired electron spins, giving rise to a very broad line. In addition, inductively coupled plasma mass spectrometry (ICP-MS) analysis was performed. This technique detects specifically metals and the Gd-to-Zn ratio was estimated to be ca. 1, confirming that one Gd-DOTA unit is present per $\mathrm{Zn}$ phthalocyanine core (Fig. S12 and Table S2).

\section{Photophysics and photochemistry}

The photophysical and photochemical properties of the DOTAphthalocyanine conjugate $\mathbf{8}$ were investigated and compared with those of the corresponding symmetrically substituted phthalocyanine $\mathbf{5}$, used as the analogous reference without DOTA unit (30). All the data commented below are summarized in Tables 1 and 2. 


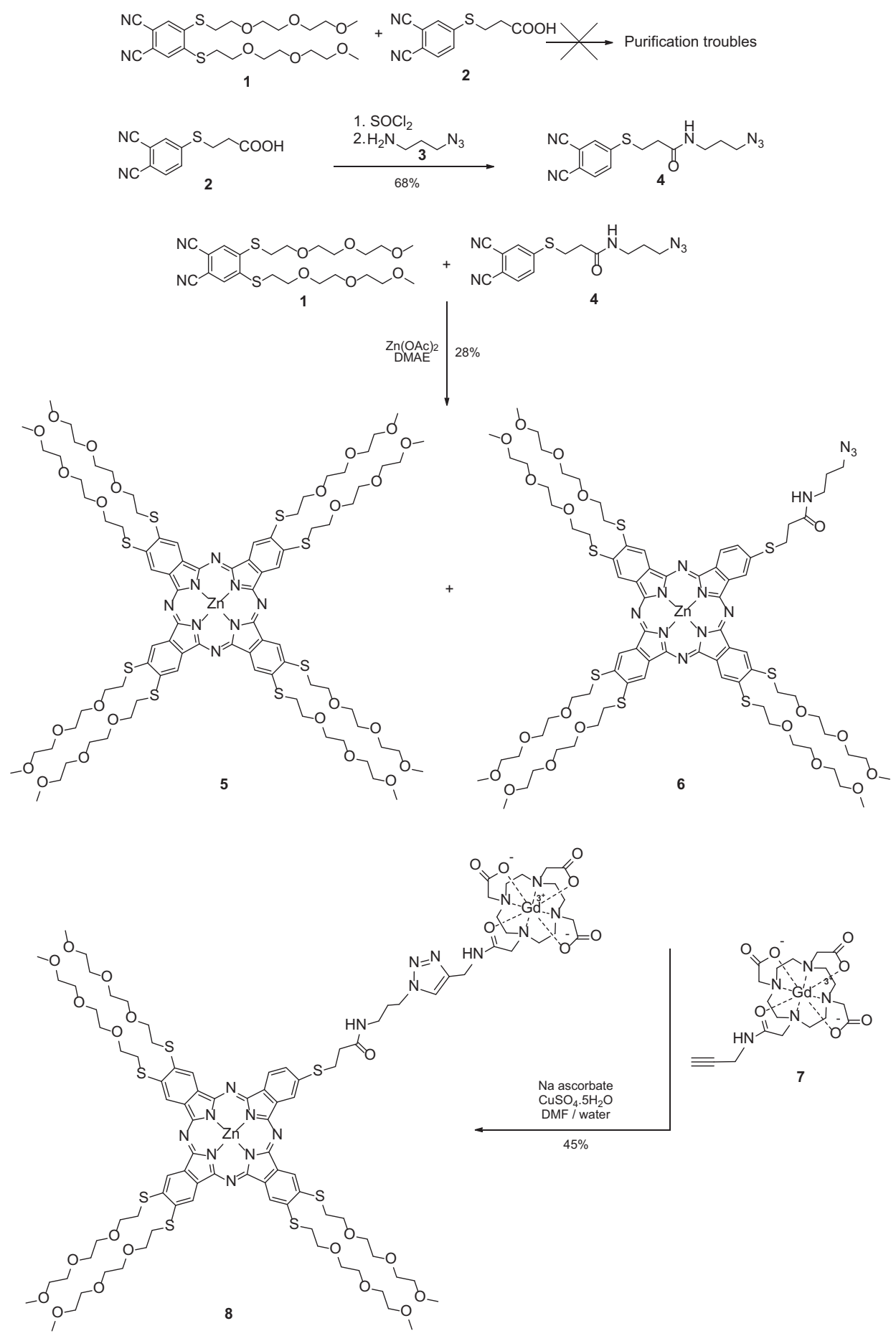

Scheme 1. Multistep synthesis of conjugate $\mathbf{8}$

Photophysical properties. The electronic absorption spectrum of conjugate 8 was measured in DMSO, DMF, DCM and $\mathrm{H}_{2} \mathrm{O}$ (Fig. 2, top). One can notice that the solubility of the conjugate is wide ranged, from very polar solvents such as water, to much more hydrophobic dichloromethane. The presence of the DOTA on $\mathbf{8}$ significantly enhanced the water-solubility compared to reference symmetric phthalocyanine 5 (30) even if the conjugate is still aggregated as evidenced by the blueshifted position and large shape of its $Q$ band. This water- solubility is a positive aspect for further biological experiments. The fact that this was due to aggregation was confirmed by the addition of Triton X-100, a surfactant known to inhibit aggregation in aqueous media (65-67). Indeed, the sharpness of the $\mathrm{Q}$ band was restored upon its addition. As further photophysical and photochemical measurements need to be conducted on monomerized (nonaggregated) molecules, the aggregation behavior of $\mathbf{8}$ was studied in different solvents (Fig. 2, bottom). 

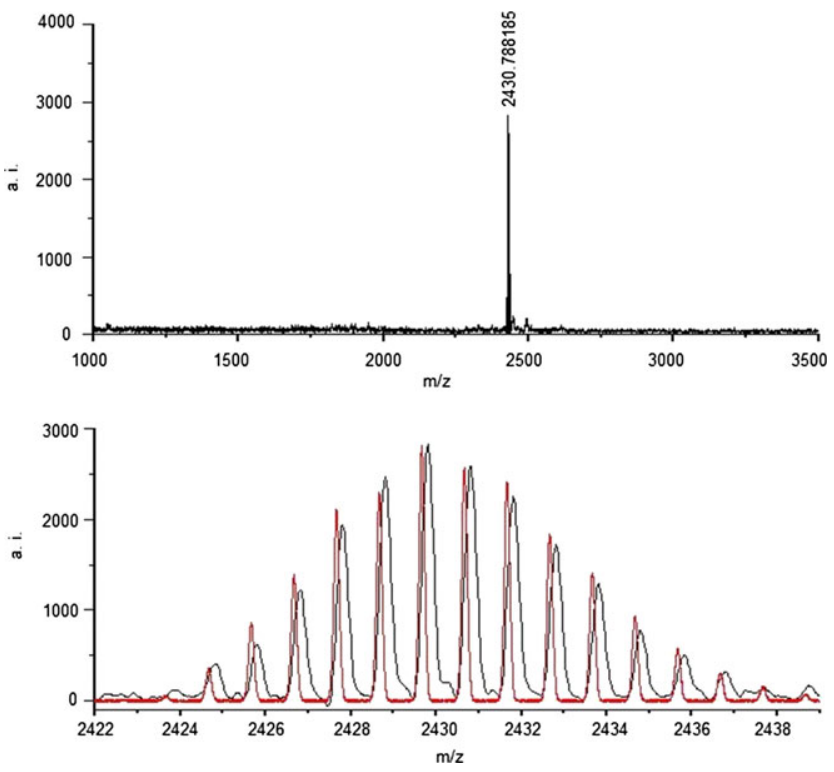

Figure 1. MALDI-TOF high-resolution mass spectrum of conjugate $\mathbf{8}$. Top: full spectrum, bottom: superposition of the theoretical (red) and experimental (black) isotopic patterns. The observed molecular ion is $[\mathrm{M}+\mathrm{H}]+$. Mass accuracy $3.82 \mathrm{ppm}$.

Table 1. Electronic absorption and fluorescence data for conjugate 8 in different solvents.

\begin{tabular}{lccccc}
\hline Solvent & $\begin{array}{c}\text { Q band } \\
\lambda_{\text {max }}, \\
(\mathrm{nm})\end{array}$ & $\begin{array}{c}\log \\
\varepsilon\end{array}$ & $\begin{array}{c}\text { Excitation } \\
\lambda_{\text {Ex }}(\mathrm{nm})\end{array}$ & $\begin{array}{c}\text { Emission } \\
\lambda_{\text {Em }} \\
(\mathrm{nm})\end{array}$ & $\begin{array}{c}\text { Stokes } \\
\text { shift } \Delta_{\text {Stokes }}, \\
(\mathrm{nm})\end{array}$ \\
\hline DMSO & 705 & 5.01 & 706 & 713 & 8 \\
DMF & 701 & 4.99 & 703 & 711 & 10 \\
$\mathrm{DCM}$ & 704 & 4.48 & 705 & 713 & 9 \\
$\mathrm{H}_{2} \mathrm{O}$ & 650 & 3.82 & 655 & - & - \\
\hline
\end{tabular}

Table 2. Photophysical and photochemical parameters of phthalocyanine-DOTA conjugate 8 in DMSO and $\mathrm{H}_{2} \mathrm{O}$.

\begin{tabular}{lllcc}
\hline Compound & Solvent & \multicolumn{1}{c}{$\Phi_{\mathrm{F}}$} & $\Phi_{\mathrm{d}}\left(\times 10^{-5}\right)$ & $\Phi_{\Delta}$ \\
\hline $\mathbf{5}$ & DMSO & $0.13(30)$ & $22.0(30)$ & 0.72 \\
$\mathbf{8}$ & DMSO & 0.15 & 3.97 & 0.67 \\
$\mathbf{8}$ & $\mathrm{H}_{2} \mathrm{O}$ & - & 10.8 & 0.10 \\
\hline
\end{tabular}

The ground-state electronic absorption spectrum of $\mathbf{8}$ in DMSO shows characteristic absorption in the Q-band region. The spectrum of this molecule exhibits monomeric behavior evidenced by a single narrow $\mathrm{Q}$ band which is typical of nonaggregated metallated phthalocyanine complexes, and it was therefore decided to conduct the next photophysical and photochemical measurements in this solvent, as well as in water which is the closest to biological medium.

Fluorescence characterization of the conjugate $\mathbf{8}$ was performed. The fluorescence emission spectrum of $\mathbf{8}$ is a mirror image of the absorption spectra, which is itself similar to the excitation spectrum (Fig. 3). Fluorescence quantum yield $\left(\Phi_{\mathrm{F}}\right)$ of phthalocyanine-DOTA conjugate $\mathbf{8}$ in DMSO is given in Table 3
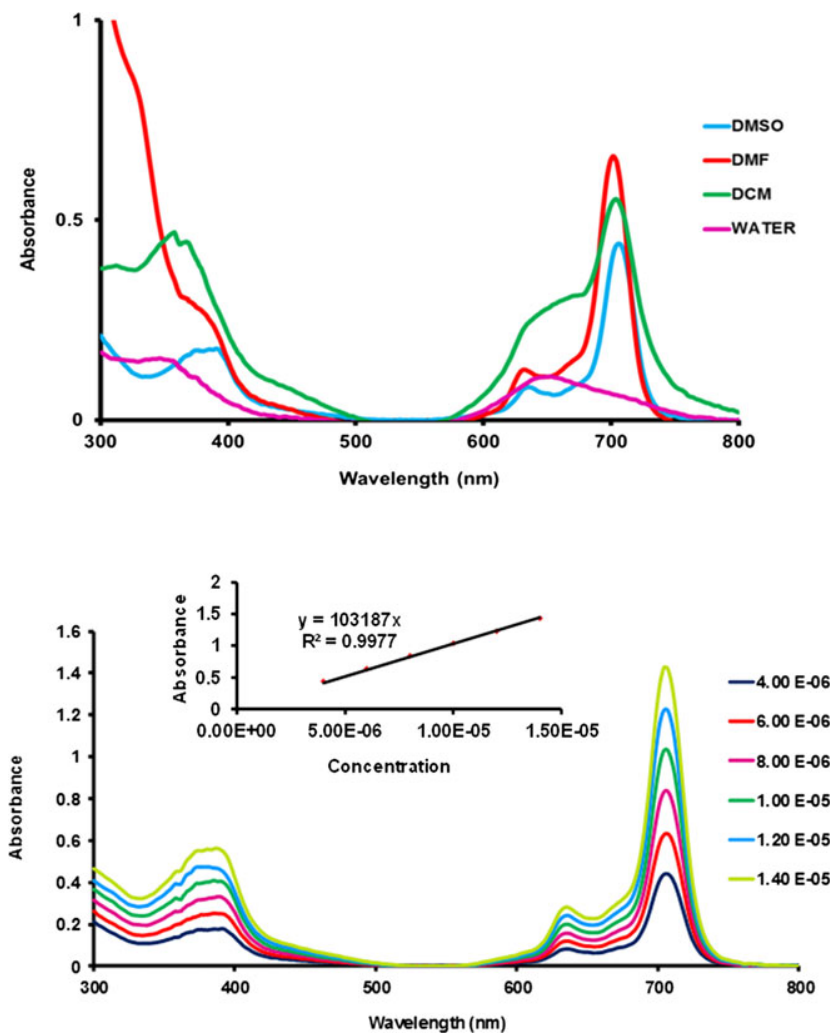

Figure 2. Top: UV-Vis spectrum of $\mathbf{8}$ in different solvents, at a $10 \mu \mathrm{M}$ concentration. Bottom: Aggregation behavior of $\mathbf{8}$ in DMSO at different concentrations: $14,12,10,8,6$ and $4 \mu \mathrm{M}$. Inset: Plot of absorbance versus concentration. The linearity of the slope means that the Beer-Lambert law is respected and that the compound is not aggregated.

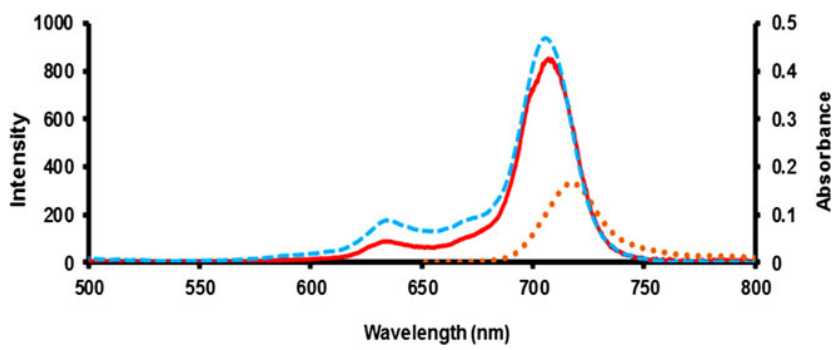

Figure 3. Absorption (dashed line), fluorescence excitation (solid line) and emission (dotted line) spectra of $\mathbf{8}$ in DMSO. Excitation wavelength $645 \mathrm{~nm}$, emission wavelength $713 \mathrm{~nm}$.

Table 3. Gd(III) ionic relaxivity of conjugate $\mathbf{8}$ and $\mathrm{Gd}(\mathrm{III})$ complexes in water at $37^{\circ} \mathrm{C}$ and $128 \mathrm{MHz}$

\begin{tabular}{lc}
\hline Compound & $r_{1}\left(\mathrm{mM}^{-1} \mathrm{~s}^{-1}\right)$ \\
\hline Conjugate 8 & 1.43 \\
Gd-595 (7) & $3.21(23)$ \\
Omniscan $^{\circledR}$ & $3.23(79)$
\end{tabular}

and has been determined using reported calculation methods (68). This molecule does not fluoresce in water, most probably due to the aggregation described above. 
As biological media are not simple water, and as we demonstrated in previous reports that phthalocyanines monomerize in the presence of biological membranes and other components (69), the fluorescence emission of conjugate $\mathbf{8}$ (observed in other solvents) is likely to be an additional useful tool for tumor visualization or photosensitizer distribution monitoring. As the sum of the quantum yields cannot exceed 1, the rather low fluorescence quantum yields can be correlated to the high singlet oxygen generation yield: the excited singlet state of compound $\mathbf{8}$ is converted into the triplet state rather than returning to its fundamental state by fluorescence emission.

Photochemical properties. The singlet oxygen quantum yield $\left(\Phi_{\Delta}\right)$ is a crucial photochemical parameter in PDT as it quantifies the ability of a photosensitizer to generate singlet oxygen. $\Phi_{\Delta}$ was determined by a comparative method based on the decomposition of DPBF in DMSO and ADMA in $\mathrm{H}_{2} \mathrm{O}$. These molecules react instantaneously with singlet oxygen via a dipolar cycloaddition, and their absorption is quenched by this reaction. Therefore, the diminution of the absorption of DPBF in DMSO at $417 \mathrm{~nm}$, and of ADMA in water at $380 \mathrm{~nm}$, is directly proportional to the singlet oxygen generated upon irradiation (see measured spectrum examples in refs 9,31 and 65). The curves in DMSO and water are presented in Fig. 4, the results are summarized in Table 2.

Molecules which are not aggregated exhibit their maximum singlet oxygen generation capability, as it is the case of $\mathbf{8}$ in DMSO, in which its $\Phi_{\Delta}$ value is 0.67 . The presence of the GdDOTA moiety has no consequence on the singlet oxygen genera-
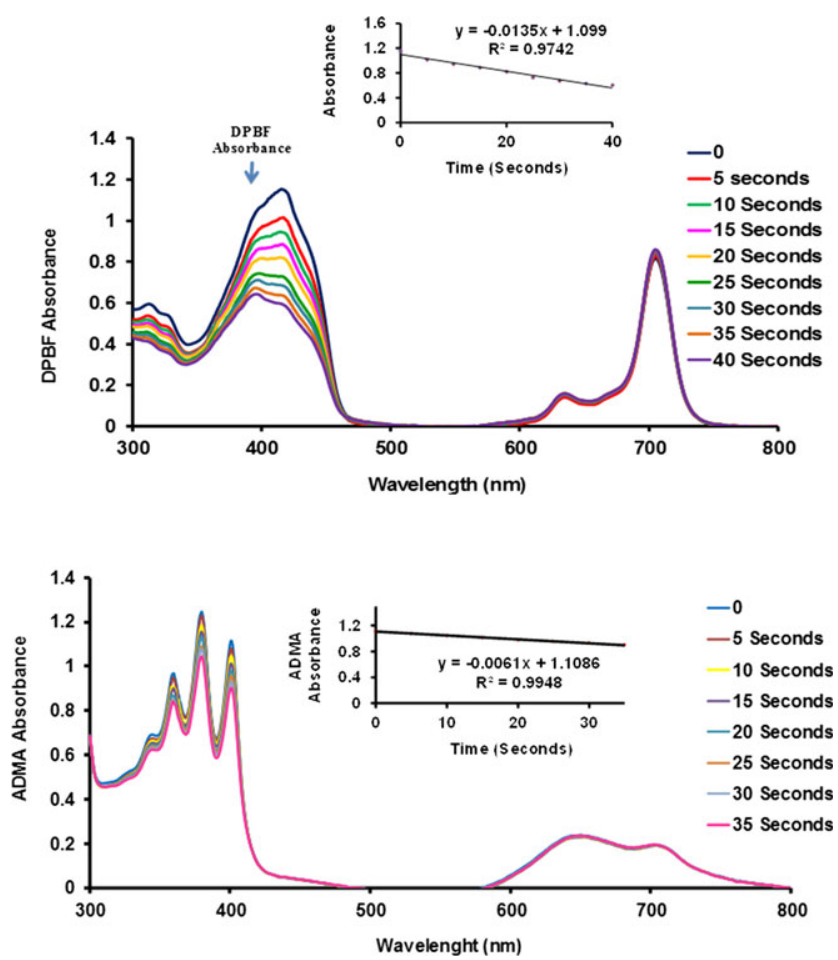

Figure 4. Top: visualization of singlet oxygen generation by 8 (concentration of $\mathbf{8}$ fixed at $10 \mu \mathrm{M}$ ) in DMSO by quenching of DPBF. Inset: Plot of DPBF absorbance versus time. Bottom: same measurements in water using ADMA (concentration of 8 fixed at $10 \mu \mathrm{M}$ ). Inset: Plot of ADMA absorbance versus time. tion ability of the phthalocyanine core, which is in the same range than the reference compound 5 (30). Minimum values to be acknowledged as a suitable photosensitizer is above 0.5 (65), therefore the photodynamic ability of conjugate $\mathbf{8}$ is satisfying. $\Phi_{\Delta}$ value in water for conjugate $\mathbf{8}$ is lower than that of in DMSO. This is due to the aggregation and to the quenching of singlet oxygen by water (65). Rather than concluding than this may prevent the use of conjugate $\mathbf{8}$ in intracellular media, one should keep in mind that cells are complex organization is likely to positively modify the aggregation state of the photosensitizer: we demonstrated that in the presence of membrane, phthalocyanine aggregated in pure water becomes monomerized and recover its photodynamic efficiency (69).

Degradation of the molecules under irradiation reflects their stability. Depending on targeted applications, different values are suitable. For photocatalysts, maximum photostability is required, when for biological photoapplications, intermediate photostability is preferred to limit risks of accumulative toxicity. Conjugate $\mathbf{8}$ and reference derivative $\mathbf{5}$ exhibited about similar stability with $\boldsymbol{\Phi}_{\mathbf{d}}$ of the order of $10^{-5}$ (Table 2), with no influence of the presence of the DOTA unit. Here, the $\Phi_{\mathrm{d}}$ value found is about the same with zinc phthalocyanine derivatives that have been synthesized before (30). Conjugate $\mathbf{8}$ is in the appropriate range for biological applications in both DMSO and $\mathrm{H}_{2} \mathrm{O}$.

\section{Contrast imaging}

The efficiency of clinically used contrast agents is expressed by their relaxivity $r_{1}$, mainly influenced by the residence time of the water molecule(s) coordinated to the central Gd(III) ion $\left(\tau_{\mathrm{M}}\right)$ and the rotational correlation time of the whole molecule $\left(\tau_{\mathrm{R}}\right)(70$ 72). In general, the clinically used contrast agents such as Omniscan ${ }^{\circledR}$ display slow water exchange rate (long $\tau_{\mathrm{M}}$ ) and fast molecular tumbling (short $\tau_{\mathrm{R}}$ ) due to their low-molecular-weight nature (73). The rotational time can be changed by increasing the molecular weight of whole molecule by conjugation of complex to a macromolecule (74-76). Meanwhile, conjugates with higher molecular weight could show much lower relaxivity than expected due to the local movements inducing a shortening of $\tau_{\mathrm{R}}$ value. These local movements can be slowed down by rigidifying the spacer between the contrast agents and macromolecule (77-79). DOTA derivatives, where the amide oxygen atom forms a 6-membered chelate ring upon coordination of $\mathrm{Gd}(\mathrm{III})$, were found to have a mean water residency time, which is within the ideal range required for our purposes.

The longitudinal relaxation rate $\left(1 / \mathrm{T}_{1}\right)$ of conjugate $\mathbf{8}$ was measured in water at various $\mathrm{Gd}^{3+}$ concentrations $(0.05,0.10$, $0.20,0.40,0.80$ and $1.60 \mathrm{mM}$ ) and is clearly concentration dependant, as can be observed on $\mathrm{T}_{1}$-weighted $\mathrm{MR}$ images (Fig. 5) where the more prominent positive contrast is achieved for compound $\mathbf{8}$ the higher concentration.

$T_{1}$ relaxivity $\left(r_{1}\right)$, was then determined from the slope of $1 / \mathrm{T}_{1}$ versus $\left[\mathrm{Gd}^{3+}\right]$ plot (Fig. 6). $r_{1}$ values of compound 8 then calculated to be $1.43 \mathrm{mM}^{-1} \mathrm{~s}^{-1}$ (Table 3). Conjugate 8 exhibited $r_{1}$ relaxivity that was compared to the values available for Gd-595 (7) and Omniscan ${ }^{\circledR}$ (Table 3), and exhibited close but weaker values, confirming that the conjugate $\mathbf{8}$ retains the contrast imaging property of the Gd-DOTA moiety. The weaker values may be attributed to the amide function on the spacer arm, likely to block the water-binding site. 


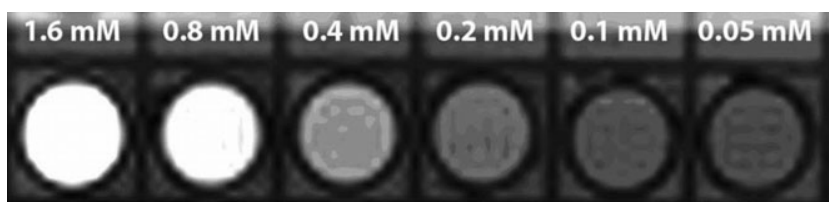

Figure 5. T1-weighed image for conjugate 8 .

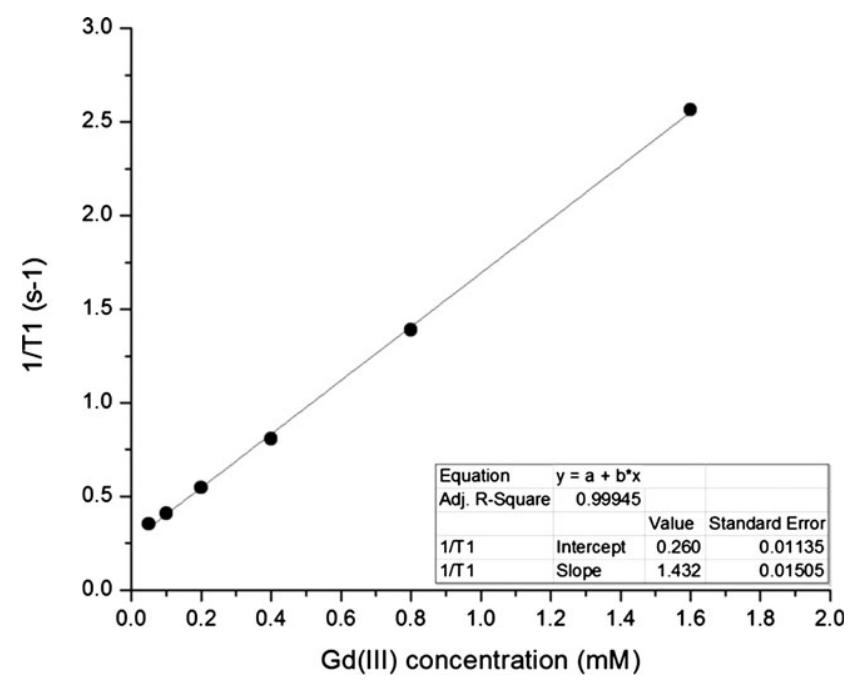

Figure 6. T1 relaxation rate versus the concentration of conjugate 8 .

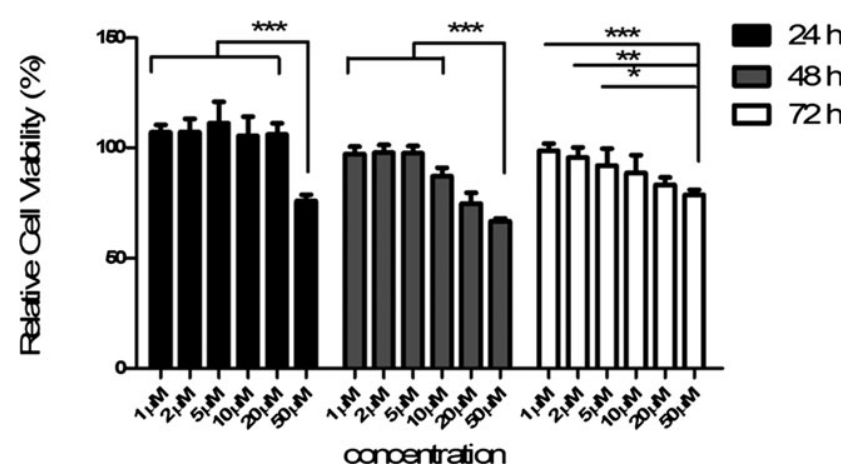

Figure 7. Exposure to 1 to $20 \mu \mathrm{M}$ of conjugate 8 for $24 \mathrm{~h}, 48 \mathrm{~h}$ and $72 \mathrm{~h}$ did not effect viability of MCF-7 cells. However, $50 \mu \mathrm{M}$ of reagent significantly decreased cell viability. Exposure to conjugate 8 reduced cell viability in a concentration-dependent manner. Cell viability was normalized to untreated cells. Data points represents mean \pm SEM with $n=4 . \quad\left({ }^{*} P=0.05,{ }^{*} P=0.01, * * * P=0.001\right.$ by one-way ANOVA/ Bonferroni multiple comparison test).

\section{In vitro compatibility assessments}

In order to analyze biocompatibility, cell viability in the absence of light was investigated, to assess the relevance of the use of conjugate $\mathbf{8}$ as a theranostic agent: a photosensitizer should actually not be toxic at the working concentrations in the absence of light. Human breast adenocarcinoma cells (MCF-7) were treated with conjugate $\mathbf{8}$ in final concentrations of 1, 5, 10, 20 and $50 \mu \mathrm{M}, 24 \mathrm{~h}$ after cell seeding $(n=4)$. After 24,48 and $72 \mathrm{~h}$ of incubation, viability of cells was evaluated by Alamar blue assay. Nontreated cells were used as control group and the viability of treated cells are shown relative to nontreated cells in Fig. 7. At 24 h, conjugate 8 caused no adverse effects on viability of cells when used between $1-20 \mu \mathrm{M}$ of concentration. However, treatment with $50 \mu \mathrm{M}$ of conjugate $\mathbf{8}$ decreased cell viability to $\sim 75 \%$. Longer exposure times (48 and $72 \mathrm{~h}$ ) induce an antiproliferative effect on MCF-7 cells for $20 \mu \mathrm{M}$ of conjugate 8, which remains not toxic at $1-10 \mu \mathrm{M}$, these concentrations causing no significant effect on cell proliferation (Fig. 7).

The cell uptake of conjugate $\mathbf{8}$ by MCF-7 cells was investigated as well. Cells were seeded in 24-well plates at a density of $5 \times 10^{3}$ cells/well. After a $24 \mathrm{~h}$ incubation period, the cells were treated with $10 \mu \mathrm{M}$ of conjugate 8 at $37^{\circ} \mathrm{C}$ for $24 \mathrm{~h}$ in a humidified incubator. The samples were analyzed with Zeiss LSM-510 confocal microscope with an oil-immersion $63 \times$ objective lens. An argon laser of $488 \mathrm{~nm}$ wavelength was used. The uptake of conjugate $\mathbf{8}$ is evidenced in Fig. 8. Further subcellular localization assays by colocalization with nuclear stains are being conducted to precisely assess the distribution of conjugate $\mathbf{8}$.

These preliminary data demonstrate the suitability of conjugate $\mathbf{8}$ for further biological investigations, currently ongoing.

\section{CONCLUSION}

A novel type of theranostic combining MRI contrast imaging and photodynamic properties has been designed and successfully synthesized. A phthalocyanine was selected for the photodynamic ability, in which a Gd-DOTA moiety was introduced to add MRI contrast imaging properties. The works presented here demonstrated the relevance of this design, as the conjugate retains the photophysical and photochemical properties of the phthalocyanine core: the singlet oxygen generation of the conjugate is in the same range as the reference without DOTA moiety. Even though the MRI contrast imaging ability of the conjugate is lowered compared to related commercial Gd complexes, the data obtained are suitable for imaging purposes. In vitro assays

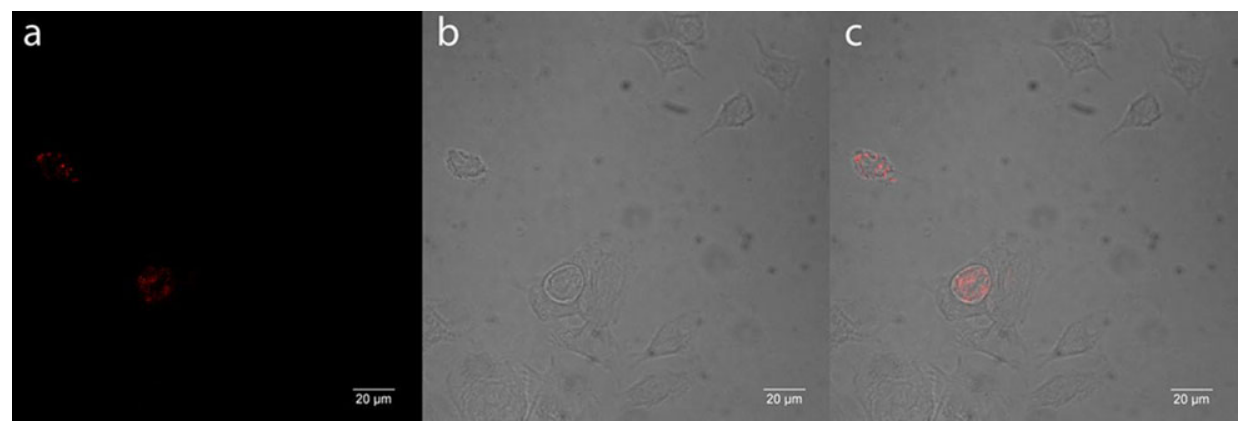

Figure 8. Cellular uptake of conjugate 8 by MCF-7 cells after incubation for 24 h at $37{ }^{\circ} \mathrm{C}$. Confocal images of MCF-7 cells treated with $10 \mu \mathrm{M}$ of conjugate $8(\mathrm{a}, \mathrm{b}, \mathrm{c})$. 
indicate an appropriate innocuousness of the conjugate at concentrations used for treatment. All these measurements together confirm the relevance of this new theranostic concept. Further biological investigations are in progress.

Acknowledgements-The Scientific and Technological Research Council of Turkey (TUBITAK) is gratefully acknowledged for his funding through the project 113R004 coupled to the COST Action TD1004.

\section{SUPPORTING INFORMATION}

Additional Supporting Information may be found in the online version of this article:

Figure S1. FT-IR spectrum of compound 4.

Figure S2. ${ }^{1} \mathrm{H}$ NMR spectrum of compound 4 (in $\mathrm{CDCl}_{3}$ ).

Figure S3. ${ }^{13} \mathrm{C}$ NMR Spectrum of compound 4 (in $\mathrm{CDCl}_{3}$ ).

Figure S4. MS (ESI) spectrum of compound 4.

Figure S5. Molecular structure of 4. Displacement ellipsoids are drawn at the $50 \%$ probability level. H-atoms are shown as small spheres of arbitrary radii.

Figure S6. FT-IR spectrum of compound 6.

Figure S7. ${ }^{1} \mathrm{H}$ NMR spectrum of compound $6\left(\mathrm{DMF}-\mathrm{d}_{7}\right)$.

Figure S8. ${ }^{13} \mathrm{C}$ NMR spectra of compound 6 .

Figure S9. High-resolution mass spectrum (MALDI-TOF) of compound 6. Top: full spectrum. The observed molecular ion are $[\mathrm{M}+\mathrm{H}]^{+}$and $[\mathrm{M}+\mathrm{H}-2 \mathrm{~N}]^{+}$. Bottom: superposition of the theoretical (red) and experimental (black) isotopic patterns.

Figure S10. FT-IR spectrum of compound 8.

Figure S11. EPR spectrum of $\mathbf{8}$ in solution (chloroform) at room temperature, recorded in the $0-8000 \mathrm{G}$ range.

Figure S12. ICP-MS calibration curves for ${ }^{66} \mathrm{Zn}$ and ${ }^{157} \mathrm{Gd}$ nuclei.

Table S1. Crystal data and refinement parameters for 4 .

Table S2. Gd(III) and $\mathrm{Zn}(\mathrm{II})$ concentrations acquired in ICPMS experiment.

\section{REFERENCES}

1. Lammers, T., S. Aime, W. E. Hennink, G. Storm and F. Kiessling (2011) Theranostic nanomedicine. Acc. Chem. Res. 44, 1029-1038.

2. Kelkar, S. S. and T. M. Reineke (2011) Theranostics: Combining imaging and therapy. Bioconjug. Chem. 22, 1879-1903.

3. Mura, S. and P. Couvreur (2012) Nanotheranostics for personalized medicine. Adv. Drug Deliv. Rev. 64, 1394-1416.

4. Sternberg, E. and D. Dolphin (1996) Pyrrolic photosensitizers. Curr. Med. Chem. 3, 239-272.

5. Pandey, R. K. (2008) Lighting up the lives of cancer patients by developing drugs for tumor imaging and photodynamic herapy: "see and treat" approach. Oncol. Issues, 22-23.

6. Ethirajan, M., Y. Chen, P. Joshi and R. K. Pandey (2011) The role of porphyrin chemistry in tumor imaging and photodynamic therapy. Chem. Soc. Rev. 40, 340-362.

7. Ogura, S. I., K. Tabata, K. Fukushima, T. Kamachia and I. Okura (2006) Development of phthalocyanines for photodynamic therapy. J. Porphyrins Phthalocyanines 10, 1116-1124.

8. Josefsen, L. B. and R. W. Boyle (2008) Photodynamic therapy and the development of metal-based photosensitiser. Met.-Based Drugs 2008, 276109, 1-24.

9. Aydın Tekdaş, D., U. Kumru, A. Gürek, M. Durmuş, V. Ahsen and F. Dumoulin (2012) Towards near-infrared photosensitisation: A photosensitising hydrophilic non-peripherally octasulfanyl-substituted Zn phthalocyanine. Tetrahedron Lett. 53, 5227-5230.
10. Burnham, P. M., M. J. Cook, L. A. Gerrard, M. J. Heeney and D. L. Hughes (2003) Structural characterisation of a red phthalocyanine. Chem. Commun. 16, 2064-2065.

11. Dabrowski, J. M., L. G. Arnaut, M. M. Pereira, K. Urbańska and G. Stochel (2012) Improved biodistribution, pharmacokinetics and photodynamic efficacy using a new photostable sulfonamide bacteriochlorin. Med. Chem. Commun. 3, 502-505.

12. Hocine, O., M. Gary-Bobo, D. Brevet, M. Maynadier, S. Fontanel, L. Raehm, S. Richeter, B. Loock, P. Couleaud, C. Frochot, C. Charnay, G. Derrien, M. Smaihi, A. Sahmoune, A. Morère, P. Maillard, M. Garcia and J.-O. Durand (2010) Silicalites and mesoporous silica nanoparticles for photodynamic therapy. Int. J. Pharm. 402, 221230.

13. Bechet, D., P. Couleaud, C. Frochot, M.-L. Viriot, F. Guillemin and M. Barberi-Heyob (2008) Nanoparticles as vehicles for delivery of photodynamic therapy agents. Trends Biotechnol. 26, 612-621.

14. Chouikrat, R., A. Seve, R. Vanderesse, H. Benachour, M. BarberiHeyob, S. Richeter, L. Raehm, J.-O. Durand, M. Verelst and C. Frochot (2012) Non polymeric nanoparticles for photodynamic therapy applications: Recent developments. Curr. Med. Chem. 19, 781-792.

15. Brevet, D., M. Gary-Bobo, L. Raehm, S. Richeter, O. Hocine, K. Amro, B. Loock, P. Couleaud, C. Frochot, A. Morère, P. Maillard, M. Garcia and J.-O. Durand (2009) Mannose-targeted mesoporous silica nanoparticles for photodynamic therapy. Chem. Commun. 12, 1475-1477.

16. Josefsen, L. B. and R. W. Boyle (2012) Unique diagnostic and therapeutic roles of porphyrins and phthalocyanines in photodynamic therapy, imaging and theranostics. Theranostics 2, 916-966.

17. Ün, I., Y. Zorlu, H. İbişoğlu, F. Dumoulin and V. Ahsen (2013) A phthaloyanine- fluorescein conjugate. Turk. J. Chem. 37, 394-404.

18. Lv, F., X. He, L. Lu, L. Wu and T. Liu (2012) Synthesis, properties and near-infrared imaging evaluation of glucose conjugated zinc phthalocyanine via click chemistry. J. Porphyrins Phthalocyanines 16, 77-84.

19. Ali, H. and J. E. Van Lier (1999) Metal complexes as photo- and radiosensitizers. Chem. Rev. 99, 2379-2450.

20. Ranyuk, E., H. Ali, B. Guérin and J. E. van Lier (2013) A new approach for the synthesis of ${ }^{18} \mathrm{~F}$-radiolabelled phthalocyanines and porphyrins as potential bimodal/theranostic. J. Porphyrins Phthalocyanines 17, 850-856.

21. Geraldes, C. F. G. C. and S. Laurent (2009) Classification and basic properties of contrast agents for magnetic resonance imaging. Contrast Media Mol. Imaging 4, 1-23.

22. Aime, S., S. G. Crich, E. Gianolio, G. B. Giovenzana, L. Tei and E. Terreno (2006) High sensitivity lanthanide(III) based probes for MRmedical imaging. Coord. Chem. Rev. 250, 1562-1579.

23. Woods, M., E. W. C. Donald and A. D. Sherry (2006) Paramagnetic lanthanide complexes as PARACEST agents for medical imaging. Chem. Soc. Rev. 35, 500-511.

24. Buhaescu, I. and H. Izzedine (2008) Gadolinium-induced nephrotoxicity. Int. J. Clin. Pract. 62, 1113-1118.

25. Caravan, P., J. J. Ellison, T. J. McMurry and R. B. Lauffer (1999) Gadolinium(III) chelates as MRI contrast agents: Structure, dynamics, and applications. Chem. Rev. 99, 2293-2352.

26. Werner, E. J., A. Datta, C. J. Jocher and K. N. Raymond (2008) High-relaxivity MRI contrast agents: Where coordination chemistry meets medical imaging. Angew. Chem. Int. Ed. 47, 8568-8580.

27. Major, L. and T. J. Meade (2009) Bioresponsive, cell-penetrating and multimeric MR contrast agents. Acc. Chem. Res. 42, 893-903.

28. Cheng, W., I. E. Haedicke, J. Nofiele, F. Martinez, K. Beera, T. J. Scholl, H. L. M. Cheng and X. A. Zhang (2014) Complementary strategies for developing Gd-free high field $\mathrm{T}_{1}$ MRI contrast agents based on $\mathrm{Mn}^{\mathrm{III}}$ porphyrins. J. Med. Chem. 57, 516-520.

29. Tamada, T., K. Ito, T. Sone, A. Yamamoto, K. Yoshida, K. Kakuba, D. Tanimoto, H. Higashi and T. Yamashita (2009) Dynamic contrast-enhanced magnetic resonance imaging of abdominal solid organ and major vessel: Comparison of enhancement effect between Gd-EOB-DTPA and Gd-DTPA. J. Magn. Reson. Imaging 29, 636-640.

30. Atilla, D., N. Saydan, M. Durmuş, A. G. Gürek, T. Khan, A. Rück, H. Walt, T. Nyokong and V. Ahsen (2007) Synthesis and photodynamic potential of tetra- and octa-triethyleneoxysulfonyl substituted zinc phthalocyanines. J. Photochem. Photobiol. A: Chem. 186, 298307. 
31. Tuncel, S., F. Dumoulin, J. Gailer, M. Sooriyaarachchi, D. Atilla, M. Durmuş, D. Bouchu, H. Savoie, R. W. Boyle and V. Ahsen (2011) A set of highly water-soluble tetraethyleneglycol-substituted $\mathrm{Zn}$ (II) phthalocyanines: Synthesis, photochemical and photophysical properties, interaction with plasmaproteins and in vitro phototoxicity. Dalton Trans. 40, 4067-4079.

32. Atilla, D., M. Durmuş, A. G. Gürek, V. Ahsen and T. Nyokong (2007) Synthesis, photophysical and photochemical properties of poly(oxyethylene)-substituted zinc phthalocyanines. Dalton Trans. 12, 1235-1243.

33. Zorlu, Y., M. A. Ermeydan, F. Dumoulin, V. Ahsen, H. Savoie and R. W. Boyle (2009) Glycerol and galactose substituted zinc phthalocyanines. Synthesis and photodynamic activity. Photochem. Photobiol. Sci. 8, 312-318.

34. Ogunsipe, A., M. Durmuş, D. Atilla, A. G. Gürek, V. Ahsen and T. Nyokong (2008) Synthesis, photophysical and photochemical studies on long chain zinc phthalocyanine derivatives. Synth. Met. 158, 839-847.

35. Lafont, D., Y. Zorlu, H. Savoie, F. Albrieux, V. Ahsen, R. W. Boyle and F. Dumoulin (2013) Monoglycoconjugated phthalocyanines: Effect of sugar and linkage on photodynamic activity. Photodiagn. Photodyn. Ther. 10, 252-259.

36. Tuncel, S., J. Fournier-dit-Chabert, F. Albrieux, V. Ahsen, S. Ducki and F. Dumoulin (2012) Towards dual photodynamic and antiangiogenic agents: Design and synthesis of a phthalocyanine-chalcone conjugate. Org. Biomol. Chem. 10, 1154-1157.

37. Tuncel, S., A. Trivella, D. Atilla, K. Bennis, H. Savoie, F. Albrieux, L. Delort, H. Billard, V. Dubois, V. Ahsen, F. Caldefie-Chézet, C Richard, R. W. Boyle, S. Ducki and F. Dumoulin (2013) Assessing the dual activity of a chalcone-phthalocyanine conjugate: Design, synthesis, and antivascular and photodynamic Properties. Mol. Pharmaceutics, 10, 3706-3716.

38. Giuntini, F., F. Dumoulin, R. Daly, V. Ahsen, E. M. Scanlan, A. Lavado, J. W. Aylott, G. Rosser, A. Beeby and R. W. Boyle (2012) Orthogonally bifunctionalised polyacrylamide nanoparticles: A support for the assembly of multifunctional nanodevices. Nanoscale $\mathbf{4}$, 2034-2045.

39. Aydın Tekdaş, D., M. Durmuş, H. Yanık and V. Ahsen (2012) Photodynamic therapy potential of thiol-stabilized CdTe quantum dotgroup 3A phthalocyanine conjugates (QD-Pc). Spectrochimica Acta Part A 93, 313-320.

40. Ranyuk, E., R. Lebel, Y. Bérubé-Lauziere, K. Klarskov, R. Lecomte, J. E. van Lier and B. Guérin (2013) ${ }^{68} \mathrm{Ga} / \mathrm{DOTA}-$ and ${ }^{64} \mathrm{Cu} / \mathrm{NOTA}-$ phthalocyanine conjugates as fluorescent/PET bimodal imaging probes. Bioconjug. Chem. 24, 1624-1633.

41. Dabak, S., V. Ahsen, F. Heinemann and P. Zugenmaier (2000) Synthesis and characterization of novel tetra and octa-triethyleneoxysulfanyl substituted phthalocyanines forming lyotropic mesophases. Mol. Cryst. Liq. 348, 111-127.

42. Yildırım, Ö., A. M. Sevim and A. Gül (2011) Novel water-soluble metallophthalocyanines supported on cotton fabric. Color. Technol. 128, 236-243.

43. Carboni, B., A. Benalil and M. Vaultier (1993) Aliphatic amino azides as key building blocks for efficient polyamine syntheses. $J$. Org. Chem. 58, 3736-3741.

44. Viguier, R. F. H. and A. N. Hulme (2006) A sensitized europium complex generated by micromolar concentrations of copper(I): Toward the detection of copper(I) in biology. J. Am. Chem. Soc. 128, 11370-11371.

45. Song, Y., E. K. Kohlmeir and T. J. Meade (2008) Synthesis of multimeric MR contrast agents for cellular imaging. J. Am. Chem. Soc. 130, 6662-6663.

46. Bruker (2012) APEX2, version 2012.10-0, Bruker AXS Inc., Madison, Wisconsin

47. Bruker (2012) SAINT, version V8.27B, Bruker AXS Inc., Madison, Wisconsin.

48. Bruker (2012) SADABS, version 2012/1. Bruker AXS Inc., Madison, Wisconsin.

49. Sheldrick, G. M. (2008) A short history of SHELX. Acta Cryst. A64 112-122.

50. Spek, A. L. (2009) Structure validation in chemical crystallography. Acta Cryst. D65, 148-155.

51. Macrae, C. F., P. R. Edgington, P. McCabe, E. Pidcock, G. P. Shields, R. Taylor, M. Towler and J. van de Streek (2006) Mercury:
Visualization and analysis of crystal structures. J. Appl. Cryst. 39, 453-457.

52. Fery-Forgues, S. and D. Lavabre (1999) Are fluorescence quantum yields so tricky to measure? A demonstration using familiar stationery products. J. Chem. Ed. 76, 1260-1264.

53. Maree, D., T. Nyokong, K. Suhling and D. Phillips (2002) Effects of axial ligands on the photophysical properties of silicon octaphenoxyphthalocyanine. J. Porphyrins Phthalocyanines 6, 373-376.

54. Ogunsipe, A., J. Y. Chen and T. Nyokong (2004) Photophysical and photochemical studies of zinc(II) phthalocyanine derivatives effects of substituents and solvents. New J. Chem. 28, 822-827.

55. Seotsanyana-Mokhosi, I., N. Kuznetsova and T. Nyokong (2001) Photochemical studies of tetra-2,3-pyridinoporphyrazines. J. Photochem. Photobiol. A: Chem. 140, 215-222.

56. Spiller, W., H. Kliesch, D. Wöhrle, S. Hackbarth, B. Roder and G. Schnurpfeil (1998) Singlet oxygen quantum yields of different photosensitizers in polar solvents and micellar solutions. J. Porphyrins Phthalocyanines 2, 145-158.

57. Brannon, J. H. and D. Madge (1980) Picosecond laser photophysics. Group 3A phthalocyanines. J. Am. Chem. Soc. 102, 62-65.

58. Ogunsipe, A. and T. Nyokong (2005) Photophysical and photochemical studies of sulphonated non-transition metal phthalocyanines in aqueous and non-aqueous media. J. Photochem. Photobiol. A: Chem. 173, 211-220.

59. Song, Y., H. Zong, E. R. Trivedi, B. J. Vesper, E. A. Waters, A. G. M. Barrett, J. A. Radosevich, B. M. Hoffman and T. J. Meade (2010) Synthesis and characterization of new porphyrazine-Gd(III) conjugates as multimodal MR contrast agents. Bioconjug. Chem. 21, 2267-2275.

60. Dumoulin, F. and V. Ahsen (2011) Click chemistry: The emerging role of the azide-alkyne Huisgen dipolar addition in the preparation of substituted tetrapyrrolic derivatives. J. Porphyrins Phthalocyanines 15, 481-504.

61. Kumru, U., F. Dumoulin, E. Jeanneau, F. Yüksel, Y. Cabezas, Y. Zorlu and V. Ahsen (2012) 4,5-, 3,6-, and 3,4,5,6-tert-Butylsulfanylphthalonitriles: Synthesis and comparative structural and spectroscopic analyses. Struct. Chem. 23, 175-183.

62. Zorlu, Y., Ü. İşçi, İ. Ün, U. Kumru, F. Dumoulin and V. Ahsen (2013) Comparative structural analysis of 4,5- and 3,6-dialkylsulfanylphthalonitriles of different bulkiness. Struct. Chem. 24, 1027-1038.

63. de la Torre, G. and T. Torres (2002) Synthetic advances in phthalocyanine chemistry. J. Porphyrins Phthalocyanines 6, 274-285.

64. de la Torre, G., C. G. Claessens and T. Torres (2000) Phthalocyanines: The need for selective synthetic approaches. Eur. J. Org. Chem. 2000, 2821-2830.

65. Durmus, M. (2012) Photochemical and photophysical characterization. In Photosensitizers in Medicine, Environment, and Security, (Edited by T. Nyokong and V. Ahsen), pp. 135-266. Springer, New York.

66. Yaraşır, M. N., M. Kandaz, A. Koca and B. Salih (2006) Functional alcohol-soluble double-decker phthalocyanines: Synthesis, characterization, electrochemistry and peripheral metal ion binding. J. Porphyrins Phthalocyanines 10, 1022-1033.

67. Kandaz, M. and A. Koca (2009) Synthesis, in situ spectroelectrochemical, in situ electrocolorimetric and electrocatalytic investigation of brown-manganese phthalocyanines. Polyhedron 28, 2933-2942.

68. Nyokong, T. and E. Anthunes (2010) Photochemical and photophysical properties of metallophthalocyanines. In The Handbook of Porphyrin Science, Vol. 24 (Edited by K. M. Kadish, K. M. Smith and R. Guilard), pp. 247-357. World Scientific Publishing Co., Singapore.

69. Pashkovskaya, A., E. Kotova, Y. Zorlu, F. Dumoulin, V. Ahsen, I. Agapov and Y. Antonenko (2010) Light-triggered liposomal release: Membrane permeabilization by photodynamic action. Langmuir $\mathbf{2 6}$, 5726-5733.

70. Aime, S., M. Botta and E. Terreno (2005) Gd(III)-based contrast agents for MRI. Adv. Inorg. Chem. 57, 173-237.

71. Hermann, P., J. Kotek, V. Kubíček and I. Lukeš (2008) Gadolinium (III) complexes as MRI contrast agents: Ligand design and properties of the complexes. Dalton Trans. 23, 3027-3047.

72. Kotková, Z., L. Helm, J. Kotek, P. Hermann and I. Lukeš (2012) Gadolinium complexes of monophosphinic acid DOTA derivatives conjugated to cyclodextrin scaffolds: Efficient MRI contrast agents for higher magnetic fields. Dalton Trans. 41, 13509-13519. 
73. Powell, D. H., O. M. N. Dhubhghaill, D. Pubanz, L. Helm, Y. S. Lebedev, W. Schlaepfer and A. E. Merbach (1996) Structural and dynamic parameters obtained from 170 NMR, EPR, and NMRD studies of monomeric and dimeric $\mathrm{Gd} 3+$ complexes of interest in magnetic resonance imaging: An integrated and theoretically selfconsistent approach. J. Am. Chem. Soc. 118, 9333-9346.

74. Venditto, V. J., A. I. S. Regino and M. V. Brechbiel (2005) PAMAM dendrimer based macromolecules as improved contrast agents. Mol. Pharm. 2, 302-311.

75. Rudovský, J., M. Botta, P. Hermann, K. I. Hardcastle, I. Lukeš and S. Aime (2006) PAMAM dendrimeric conjugates with a Gd-DOTA phosphinate derivative and their adducts with polyaminoacids: The interplay of global motion, internal rotation, and fast water exchange. Bioconjug. Chem. 17, 975-987.

76. Langereis, S., A. Dirksen, T. M. Hackeng, M. H. P. van Genderen and E. W. Meijer (2007) Dendrimers and magnetic resonance imaging. New J. Chem. 31, 1152-1160.
77. Polášek, M., P. Hermann, J. A. Peters, C. F. G. C. Geraldes and I Lukeš (2009) PAMAM dendrimers conjugated with an uncharged gadolinium(III) chelate with a fast water exchange: The influence of chelate charge on rotational dynamics. Bioconjug. Chem. 20, 2142-2153.

78. Mastarone, D. J., V. S. R. Harrison, A. L. Eckermann, G. Parigi, C. Luchinat and T. J. Meade (2011) A modular system for the synthesis of multiplexed magnetic resonance probes. J. Am. Chem. Soc. 133, 5329-5337.

79. Aime, S., A. Barge, J. I. Bruce, M. Botta, J. A. K. Howard, J. M. Moloney, D. Parker, A. S. De Sousa and M. Woods (1999) NMR, relaxometric, and structural studies of the hydration and exchange dynamics of cationic lanthanide complexes of macrocyclic tetraamide ligands. J. Am. Chem. Soc. 121, 5762-5771. 